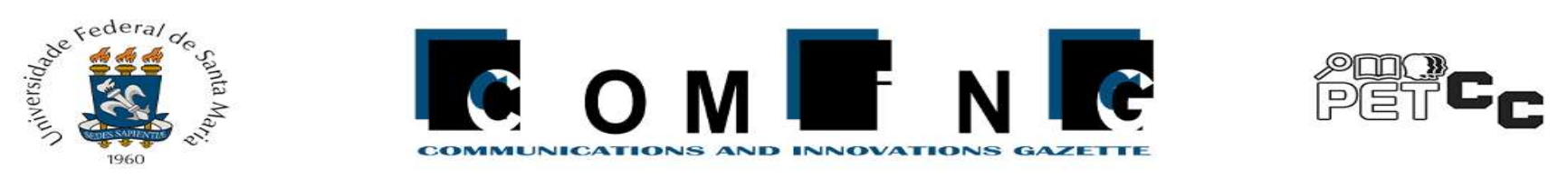

\title{
Desenvolvimento do Pensamento Computacional através da Criação de Aplicativos
}

\author{
Karine Cunha C. Mariquito ${ }^{1}$, Guilherme Quirino de Andrade ${ }^{1}$, Túlio Santos Resende ${ }^{1}$, \\ Érica Gomes Fernandes ${ }^{1}$, Raphael Fidélis Guerson ${ }^{1}$, \\ Gabriella C. B. Costa Dalpra ${ }^{1}$, Lindolpho O. de Araújo Júnior ${ }^{1}$ \\ Centro Federal de Educação Tecnológica de Minas Gerais \\ CEFET - MG - Leopoldina - Brasil \\ karinecunhacosta, guilhermeqda, tulimresende \{@gmail.com\} \\ ericagomesfernandes15, rapha.guerson \{lgmail.com\} \\ gabriella, lindolpho \{ @efetmg.br\}
}

\begin{abstract}
This work presents the processes for the construction of the application development course for mobile devices, using the MIT App Inventor. The objective of the course was to introduce computational thinking to the students involved creatively, using their own cell phones to develop applications, encouraging them, with the contents covered, to solve problems in their daily lives. This article presents all the theoretical foundations used for the construction, teaching and evaluation methodology applied in the course, the work also presents the challenges faced in teaching due to the Covid-19 pandemic and, finally, discusses the results obtained by the course, through of the self-assessment form applied to the students involved.
\end{abstract}

Resumo. Este trabalho apresenta os processos para a construção do curso de desenvolvimento de aplicativos para dispositivos móveis, utilizando o MIT App Inventor. O objetivo do curso foi introduzir o pensamento computacional nos alunos envolvidos de forma criativa, utilizando o próprio celular para o desenvolvimento de aplicações, estimulando-os, com os conteúdos abordados, a resolver problemas de seu cotidiano. Este artigo apresenta toda a fundamentação teórica utilizada para a construção, metodologia de ensino e avaliação aplicados no curso, o trabalho apresenta também os desafios enfrentados no ensino devido à pandemia de Covid-19 e, por fim, discute os resultados obtidos pelo curso, através do formulário de autoavaliação aplicado aos estudantes.

\section{Introdução}

A computação e o mundo digital estão inseridos intensamente em todas as áreas da sociedade. Neste cenário, é relevante o desenvolvimento do pensamento computacional para a inovação, evolução e desenvolvimento da comunidade. Além disso, ao fomentar o desenvolvimento do pensamento computacional contribui-se para a evolução da habilidade de resolução de problemas do cotidiano, de forma organizada e metódica [SBC 2018].

Uma forma de estimular o pensamento computacional se dá através do desenvolvimento de aplicativos para dispositivos móveis, pois impulsiona a criatividade e estimula o desenvolvimento de aplicações para resoluções de problemas do cotidiano com o uso do celular. 
Este trabalho aborda a construção de um curso para o desenvolvimento de aplicativos para dispositivos móveis ofertado para a comunidade estudantil, com foco em estudantes de escolas públicas do ensino médio e ensino fundamental. O objetivo do curso foi de introduzir o pensamento computacional para que fosse possível estimular o desenvolvimento da capacidade de resolução de problemas dos envolvidos. A ferramenta utilizada para o ensino de desenvolvimento de aplicativos móveis foi o MIT App Inventor ${ }^{1}$, que é uma plataforma intuitiva e simples de aprender, principalmente por usar programação em blocos. O projeto de extensão precisou enfrentar o desafio de se adaptar ao aprendizado remoto devido à pandemia de Covid-19, por isso a metodologia de ensino e a avaliação dos alunos foram todas construídas levando essa situação em consideração.

Este artigo está estruturado como segue: a Seção 2 apresenta conceitos sobre o pensamento computacional, sua aprendizagem e a ferramenta utilizada para o ensino da mesma neste trabalho, o MIT App Inventor. A Seção 3 apresenta os trabalhos relacionados que serviram de base teórica para este artigo. Posteriormente, a Seção 4 aborda a construção e todo o conteúdo de ensino do curso. Em seguida, a Seção 5 apresenta os detalhes e resultados da avaliação e desempenho dos alunos envolvidos e, por fim, a Seção 6 apresenta as considerações finais do trabalho.

\section{Pensamento Computacional e sua Aprendizagem}

Atualmente, o uso de dispositivos computacionais se tornou costumeiro entre todas as faixas de idade. Porém, a programação de computadores não é comumente inserida na educação básica como ensino de informática. Isso acarreta no déficit de 200 mil profissionais na área de computação e desenvolvimento em 2014, estimado em 750 mil em 2020, como mostrado no Índice Brasscom de Convergência Digital (IBCD). Isso se dá pela baixa demanda e alta evasão dos cursos da área da computação [BRASSCOM 2012]. Um dos possíveis fatores explicativos para o fenômeno pode ser a falta de conhecimento adequado sobre a área. Porém, com o constante crescimento da computação, ela já pode ser considerada uma ciência básica [Barcelos 2012].

O pensamento computacional, citado pela primeira vez por Wing (2006), se refere, principalmente, ao processo de pensamento que envolve expressar soluções para problemas computacionais através de algoritmos [Wing 2011]. Porém, ele não se limita a isso, pois não é uma habilidade que apenas cientistas devem possuir, mas qualquer pessoa, uma vez que envolve resolução de problemas, usando de abstração e decomposição, é mais que apenas programar um computador [Wing 2006].

O desafio de se ensinar o pensamento computacional no ensino básico está no desenvolvimento de disciplinas que não apenas introduzam jovens à programação de computadores, mas também aos fundamentos da computação enquanto ciência [França 2015]. Isso requer professores capacitados em não apenas ensinar programação, mas prover a todos os professores uma formação na área de Computação, articulando o pensamento computacional de forma interdisciplinar.

A escolha do MIT App Inventor como ferramenta de aprendizagem e desenvolvimento do pensamento computacional para o curso ofertado pelo projeto de extensão Mundo Maker se deu porque a plataforma apresenta uma linguagem de programação em

\footnotetext{
${ }^{1} \mathrm{http}: / /$ appinventor.mit.edu/
} 
blocos simples e interativa. Ela facilita muito o aprendizado pois suas ferramentas de edição de tela e de programação ficam à mostra para o usuário experimentar, ver o funcionamento e aplicar, além disso é possível ler uma descrição de cada elemento explicando sua funcionalidade. A ferramenta MIT App Inventor é descrita em detalhes na Subseção 2.1 .

\subsection{Ferramenta de Ensino: MIT App Inventor}

A ferramenta MIT App Inventor oferece um ambiente de programação visual e orientada a eventos, ou seja, o comportamento dos componentes depende dos eventos ocasionados pela interação entre a aplicação [Gomes and de Melo 2013].

Tal ferramenta foi desenvolvida pela Google e pelo Massachusetts Institute of Technology (MIT)[Gomes and de Melo 2013], destinada à criação de aplicativos para dispositivos móveis que sejam baseados no sistema operacional Android. A criação de uma aplicação no MIT App Inventor é feita por meio de dois mecanismos: o App Inventor Designer que é utilizado para o desenvolvimento do design da aplicação e o Blocks Editor, responsável pela criação de toda a parte lógica do aplicativo.

A Figura 1, contextualiza o uso do App Inventor Designer, onde é criado toda a parte da interface com o usuário, possibilitando a inserção de componentes como imagens, animações, botões que formam todo o design da aplicação.

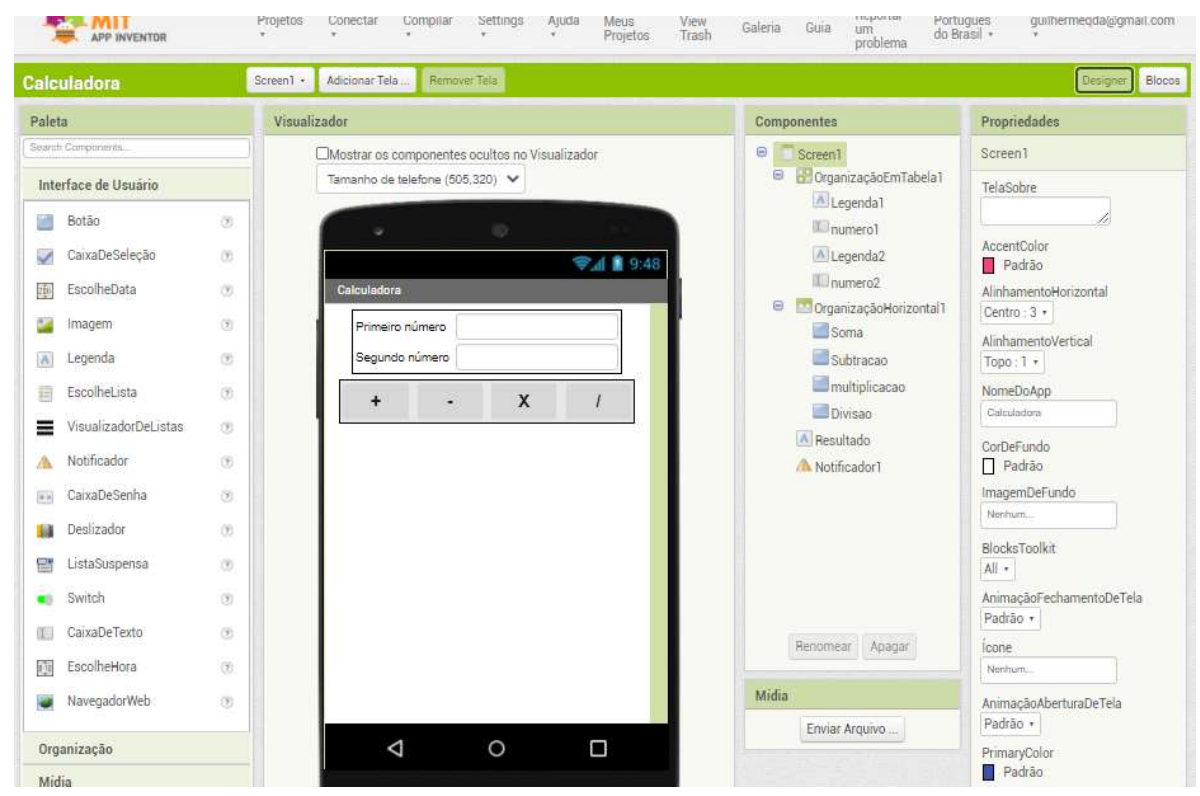

Figura 1. App Inventor Designer.

A Figura 2, mostra onde se realiza a programação da parte lógica da aplicação, controlando o comportamento dos componentes presentes no App Inventor Designer por meio da programação de blocos conectáveis. Estes, por sua vez, substituem as linhas de código, que podem ser eventos, métodos e/ou estruturas lógicas condicionais e eventos provenientes da interação do usuário com o celular e os componentes presentes na interface do aplicativo desenvolvido.

É importante destacar também que a ferramenta em questão possibilita os testes em dispositivo móveis em tempo real, ou seja, é possível acompanhar as modificações no 


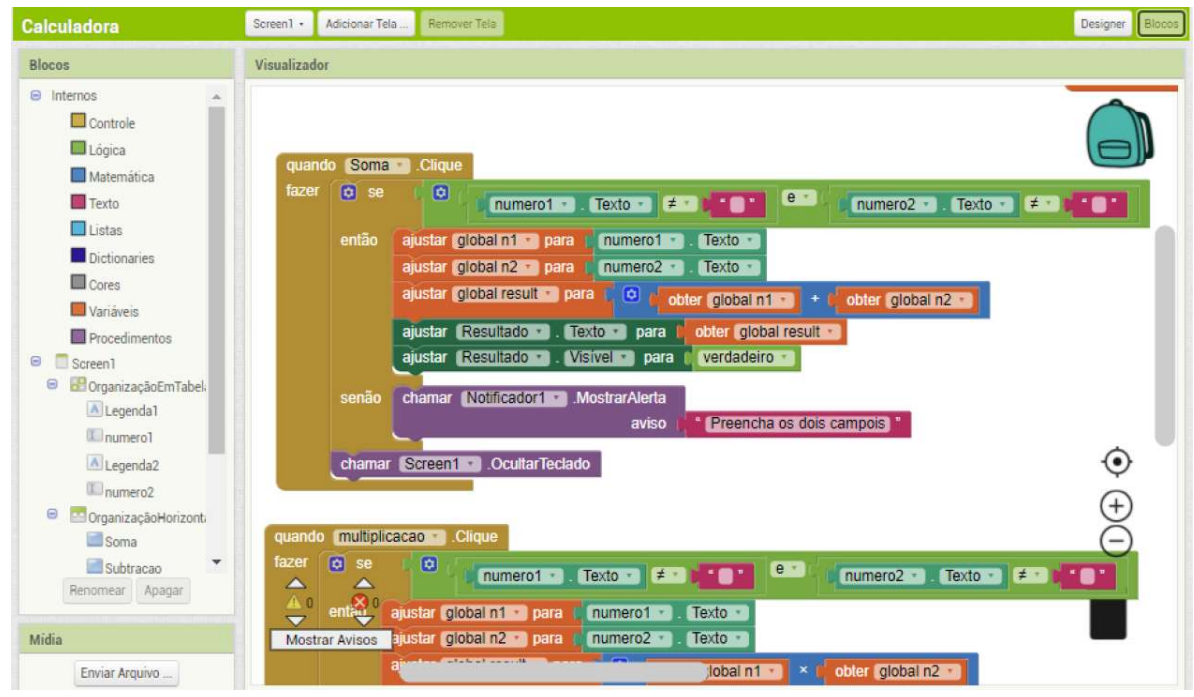

Figura 2. App Blocks Editor.

aplicativo à medida que estas são desenvolvidas.

\section{Trabalhos Relacionados}

Diversos trabalhos são encontrados na literatura explorando as funcionalidades do MIT App Inventor para a área da educação e ensino de programação. $\quad \mathrm{O}$ artigo publicado por Antonio Braz Finizola no Congresso Brasileiro de Informática na Educação [Finizola et al. 2014], apresenta uma proposta de minicurso de programação utilizando o MIT App Inventor aplicado à uma turma de $1^{\circ}$ ano do ensino médio da rede pública. Seu trabalho buscou promover a introdução de conceitos básicos de programação de maneira lúdica e foi possível observar a importância de estratégias que promovam a solução de problemas de forma atrativa.

O trabalho publicado pelo Sergio Crespo Coelho da Silva Pinto e Marcelo Simas Mattos na revista Espaço Pedagógico [Pinto and Mattos 2019] utilizou o MIT App Inventor como ferramenta de um modelo de aprendizado baseado em desenvolvimento de jogos como uma alternativa de ensino-aprendizagem em disciplinas escolares. O modelo foi aplicado em uma turma de $1^{\circ}$ período de técnico em informática integrado ao ensino médio e envolveu a criação de jogos relacionados com a disciplina de matemática.

Visto que existem outras plataformas que auxiliam no desenvolvimento do pensamento computacional por meio da programação em blocos, a seguir são brevemente apresentados alguns trabalhos relacionados que utilizam deste mesmo artifício.

Medeiros e Wünsch apresentam uma proposta que utiliza o software TinkerCAD para o ensino de programação em robótica para alunos do ensino fundamental, abrangendo 117 alunos no total e envolvendo a programação em arduino com o uso da programação em blocos [De Medeiros and Wünsch 2019].

[Batista et al. 2016] faz o uso da plataforma Scratch para o ensino de programação. Tal ferramenta faz o uso de programação em blocos para criar estórias, jogos e animações. O trabalho propõe atividades para serem desenvolvidas pelos alunos de acordo com o nível no qual se encontram na escola, o projeto envolveu estudantes desde o ensino 
fundamental até o ensino superior.

Diferentemente dos trabalhos citados anteriormente, o presente artigo apresenta uma proposta para oferta de um curso online, e não presencial. Esse modelo foi imposto por consequência das medidas de isolamento social, devido à Covid-19. O curso abordou o conteúdo visando atender um público-alvo formado por estudantes de ensino fundamental e médio. Para isso, utilizou-se uma abordagem com foco no desenvolvimento do pensamento computacional, utilizando como ferramenta de ensino o MIT App Inventor devido ao fato de se tratar de uma ferramenta usada para criação de aplicativos, podendo desta maneira causar maior interesse por parte dos alunos, visto que se trata de um mecanismo altamente utilizado na era atual, além do fato que o material necessário para se desenvolver as aplicações no curso eram o celular e o computador, tornando possível o acesso por uma quantidade maior de alunos.

\section{A Construção do Curso}

O curso de MIT App Inventor foi idealizado para entregar uma visão superficial e introdutória da lógica computacional, mas também despertar nos alunos, o interesse em programação e ciências da computação. Nesse contexto, era fundamental que o curso tivesse uma abordagem fácil de aprender e criativa, por isso os aplicativos desenvolvidos em aula, além de ensinar programação, foram pensados para chamar atenção e motivar o aluno, ainda mais, a buscar esse tipo de conteúdo. Ao invés de a aplicação se adaptar ao conteúdo, o conteúdo é que se adaptou à aplicação.

O curso foi estruturado para acontecer em seis aulas de 1 hora em formato online, devido às políticas de isolamento social impostas para conter a proliferação da Covid-19. Cada aula foi pautada no desenvolvimento de um aplicativo, e a cada novo aplicativo, aumentava-se a complexidade do mesmo. Além disso, ao final de cada aula, era passado um desafio para que os alunos reforçassem os conhecimentos adquiridos em aula. Os ministrantes os instigavam a sempre ir além do desafio, buscando informações adicionais das que eram fornecidas pelo curso. Dessa forma, os conceitos de programação eram introduzidos gradativamente, de acordo com a necessidade do problema e também conforme a evolução do aprendizado do aluno.

Na primeira aula, apresentou-se a plataforma do MIT app Inventor, mostrando o ambiente de design de tela do aplicativo, quais elementos de tela poderiam ser criados e como customizá-los. Foi apresentado também o ambiente de programação, onde é possível ver os blocos com os quais a lógica do aplicativo é criada, como os blocos são encaixados e como cada elemento de tela possui blocos diferentes específicos para suas funções. Após isso, foi construído um aplicativo chamado "Olá Mundo". O aplicativo continha uma legenda com a frase "Olá Mundo" e três botões com cores diferentes e rótulos referentes às suas respectivas cores. Ao clicar em um botão, a cor da frase assumia a cor do botão selecionado. Esse aplicativo introdutório apresentava apenas conceitos de customização dos próprios elementos de tela e a tela principal, o resultado deste aplicativo pode ser visualizado na Figura 3(a). Como desafio foi proposto aos alunos a criação de um aplicativo chamado "Tela de Login" utilizando legendas, botões e caixas de texto.

Na segunda aula foi resolvido o desafio proposto na aula anterior. Durante a solução do app foi introduzido o conceito da estrutura condicional "se então, se não". Em seguida, foi criado o aplicativo "Calculadora", mostrado na Figura 3(b). Neste aplicativo 
foi introduzido o conceito de variável utilizando os blocos de "inicialização de variável", "ajustar variável" e "obter variável", além de utilizar os blocos de operações matemáticas. Ao final da aula foi proposto o desafio de criar as outras três operações básicas (subtração, multiplicação e divisão) para o mesmo aplicativo.

$\mathrm{Na}$ terceira aula foi proposta a criação do aplicativo "Animais App", ilustrado na Figura 3(c) . Para esse aplicativo foram entregues aos alunos diversas figuras e áudios de animais. Foi ensinado como carregar mídias para a plataforma do MIT App Inventor para customizar o aplicativo, alterando o fundo, customizando botões, plotando imagens e reproduzindo sons. Além disso, foi mostrado como criar mais de uma tela e como transitar entre elas. O Aplicativo "Animais App" tinha uma tela inicial totalmente customizada (uma imagem de fundo e um botão de iniciar em formato de osso). Ao apertar o botão iniciar o aplicativo deveria abrir a segunda tela. Nela deveria ter três Botões com nomes de animais, ao clicar em cada botão a imagem de cada animal deveria aparecer na tela ao mesmo tempo que o som do respectivo animal deveria ser reproduzido. Ao final da aula foi proposto um desafio de acrescentar um quarto botão para mais um animal, cujas mídias estavam incluídas no pacote entregue aos alunos, e a criação de uma lista suspensa, utilizando o elemento "Lista suspensa", com a opção de dois idiomas, Português e Inglês, para que ao selecionar a opção "inglês" alterasse o rótulo de todos os botões. Para cumprir o desafio, foi mostrado aos alunos como configurar a estética da lista e preencher os elementos.

$\mathrm{Na}$ quarta aula foi solucionado o desafio proposto na aula anterior, mostrando o conceito de variável interna que é utilizado no bloco "quando.ListaSuspensa1.DepoisDeSelecionar" para comparar os rótulos dos elementos da lista. Nessa aula foi desenvolvido o aplicativo "Paint", mostrado na Figura 3(d), utilizando o elemento "Pintura", que nada mais é do que uma quadro branco para desenho. O aplicativo possuía seis botões de cores diferentes que, ao serem acionados, mudava a cor do pincel de pintura. Além disso, foi falado um pouco sobre os sensores mais comuns em celulares e utilizando o elemento "Sensor Acelerômetro". Com isso, o aplicativo teria a funcionalidade de "apagar o desenho" quando o celular fosse chacoalhado. O desafio proposto no fim da aula foi livre para que os alunos explorassem a ferramenta de pintura colocando mais cores para o aplicativo.

Na quinta aula foi criado o aplicativo "Me Leva", ilustrado na Figura 3(e). A proposta desse aplicativo consiste em permitir ao usuário usar o sensor de localização para salvar a coordenada de algum lugar ao qual o mesmo quisesse voltar depois, quando apertasse o botão "Me Leva". Para essa aplicação foram usados, além do sensor de localização, o TinyDB, que é o Banco de Dados utilizado no MIT App Inventor e o Iniciador de Atividades, que é usado para inicializar outro aplicativo, nesse caso, o Google Maps.

Enfim, a última aula foi pensada para ser uma oficina de ideação, buscando instigar os alunos a pensarem em como utilizar os conhecimentos adquiridos no curso para resolver algum problema do seu dia a dia. Nesta aula foi utilizada a ferramenta Trello 2 como ferramenta de organização de ideias. Os ministrantes instigaram os alunos a pensar em problemas reais com questionamentos do tipo: "Quais são os problemas?", "Como podemos solucionar?", "Como podemos desenvolver um aplicativo para resolver

\footnotetext{
${ }^{2} \mathrm{https}: / /$ trello.com/
} 
esse problema?", "Quais ferramentas devemos procurar para o desenvolvimento desse aplicativo?". Dessa forma, os alunos finalizaram o curso com várias ideias e um caminho mais claro de como eles podiam resolver problemas de seu cotidiano utilizando o pensamento computacional e tecnologias como o próprio celular.

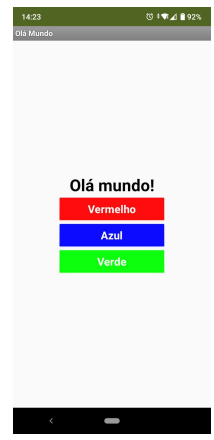

(a) Olá Mundo

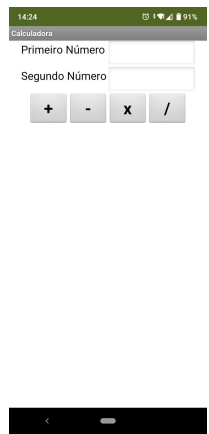

(b) Calculadora

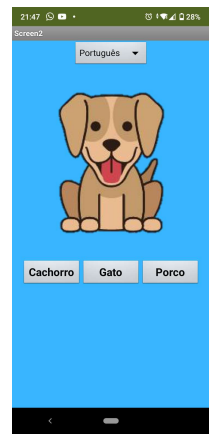

(c) Animais

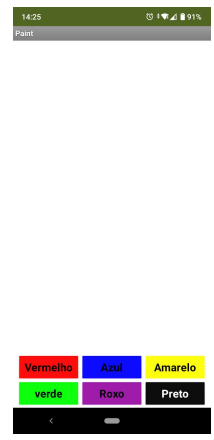

(d) Paint

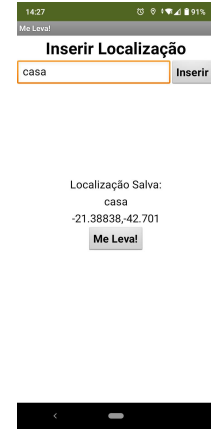

(e) MeLeva

Figura 3. Aplicativos desenvolvidos no curso.

\section{Aplicação do Curso}

O projeto, incialmente, teve como proposta a democratização do ensino, oferecendo o conhecimento a toda comunidade estudantil, tendo como foco os alunos do ensino fundamental e ensino médio de escolas públicas. Porém, devido à pandemia de Covid-19, o projeto de extensão precisou sofrer alterações, abrindo as portas para alunos de ensino superior e até alunos com doutorado. No total, foram 16 alunos selecionados no curso, mas dois destes não compareceram nas aulas. A equipe era formada por um ministrante $\mathrm{e}$ 2 monitores que ajudavam os alunos em problemas técnicos e colaboravam com o ministrante no que fosse necessário.

A seleção do curso ocorreu através de um formulário em que a preferência foi concedida ao público-alvo do projeto (os alunos do ensino fundamental e ensino médio de escolas públicas), seguidos de alunos de ensino superior, classificados quanto ao período do candidato em ordem crescente e, em seguida os candidatos já formados completaram as vagas.

Como meio de comunicação dos integrantes do projeto com os alunos foi criado um grupo no WhatsApp, tendo como objetivo manter um canal de contato para eventuais dúvidas, problemas técnicos dos alunos e também para acesso ao link da aula. As aulas foram lecionadas na plataforma de videoconferência do Google, o Meet ${ }^{3}$. A Figura 4 mostra uma captura de tela de uma das aulas online ofertadas.

\subsection{O Processo de Avaliação}

Com o intuito de analisar o desempenho dos alunos participantes e avaliar a evolução destes, foi elaborado um formulário através da plataforma Google forms ${ }^{4}$. Para isso, reuniuse a equipe do projeto para selecionar as perguntas que melhor avaliassem os resultados

\footnotetext{
${ }^{3}$ https://meet.google.com/

${ }^{4}$ https://docs.google.com/forms/d/17T1NB69VHSh19JAq7tb9z04pdGemCBIK75DEH0Naww0
} 


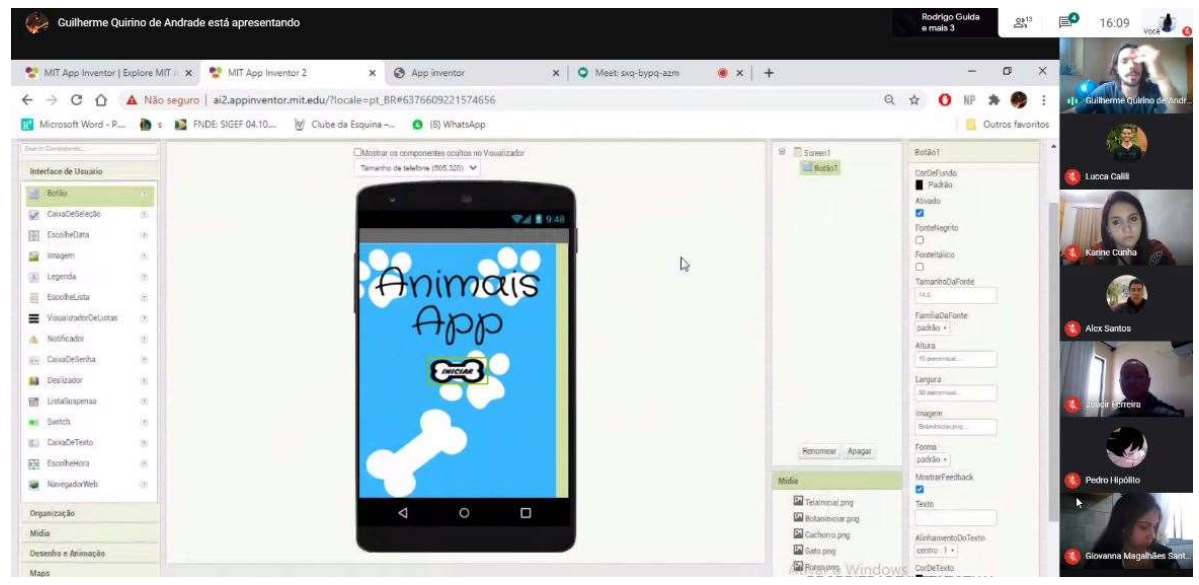

Figura 4. Aula ofertada na plataforma Google Meet.

dos aprendizados, sendo baseadas no [Silvano 2018] em que o aluno deverá fazer uma autorreflexão sobre os próprios conhecimentos e ter o papel principal sobre a sua própria avaliação.

A forma de avaliação supracitada destoa das práticas tradicionais de avaliação que focam apenas em analisar os resultados, sem considerar todo o contexto em que o aluno está inserido e a evolução do seu pensamento sobre o conteúdo aprendido. Dessa forma, o aprendizado não é tratado com uma visão binária entre saber e não saber sobre o determinado assunto, mas sim de forma analógica, analisando mais aspectos do conhecimento. Como elucida Paulo Freire em "Peregrinações: os Garros"[Freire 2002], "Não há saber mais ou saber menos: há saberes diferentes".

O formulário foi composto por 9 perguntas que avaliam sobre o raciocínio lógico, a criatividade, a participação durante a aula, o conhecimento adquirido, se o curso incentivou a continuar buscando novos conhecimentos e se os alunos estariam motivados a continuar desenvolvendo conhecimento na área. O link de acesso ao formulário foi disponibilizado aos alunos no final do curso, após concluírem todas as aulas. A pesquisa foi realizada com os 14 alunos participantes do curso de MIT App Inventor.

\subsection{Análise dos Resultados}

Em decorrência do formulário aplicado, foi possível coletar os dados necessários para a composição dos gráficos de acordo com as perguntas realizadas. Cada gráfico contém um tipo de retorno avaliativo e exibe a contagem de respostas ou notas, podendo variar em uma escala de "0"a "5"ou entre "nada"a "extremamente".

Para entender sobre o conhecimento prévio dos alunos, aplicou-se duas perguntas que consistem em entender sobre o nível de raciocínio lógico e o quão criativo eles se consideravam. As Figuras 5(a) e 6(a) exibem o retorno dos alunos.

A Figura 5(a) apresenta uma boa distribuição entre os dados, possuindo valores em todas as respostas. Nota-se que os resultados da pesquisa estão concentrados entre "muito criativo"e "moderadamente criativo"e, portanto, estando entre os extremos das respostas. Essa análise permite dizer que, apesar de haver uma defasagem entre o nível dos alunos, a maioria já apresentava algum sinal de criatividade. 


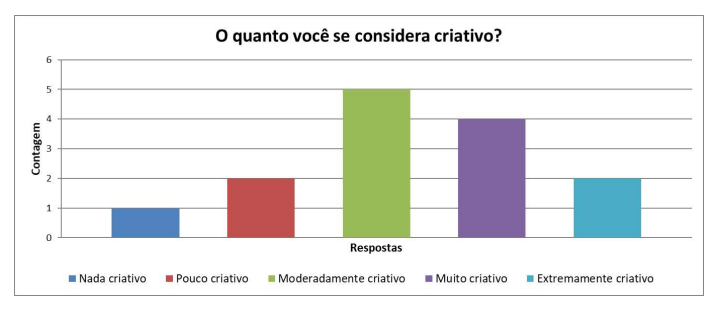

(a) Avaliação da criatividade antes da realização do curso.

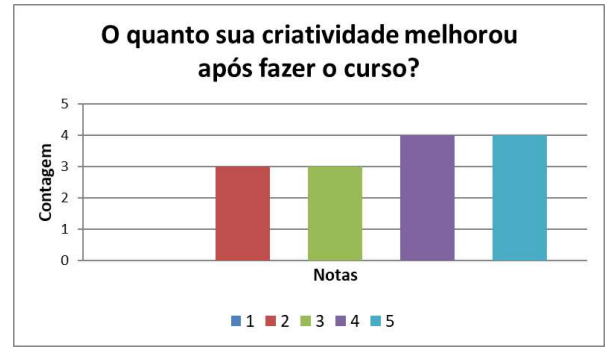

(b) Mudança na criatividade.

Figura 5. Análise da Criatividade

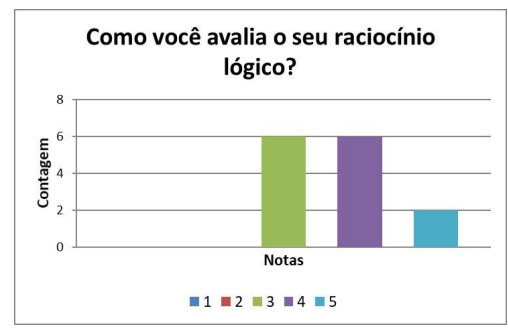

(a) Raciocínio Lógico antes do curso.

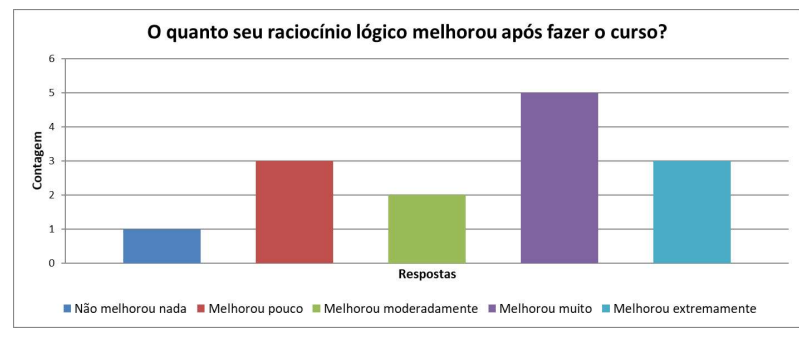

(b) Mudança no raciocínio lógico.

Figura 6. Análise do Raciocínio Lógico.

Novamente, os dados das respostas da Figura 6(a) se encontram concentrados nos valores intermediários, assim como na Figura 5(a), porém, nesse caso não há nenhuma ocorrência dos valores "1"e "2"e o valor máximo "5"aparece em apenas dois casos. Diante disso, é possível dizer que a distribuição dos valores é pequena, mostrando que a maioria dos alunos já carregavam um certo grau de raciocínio lógico, mas que este ainda pode ser melhor trabalhado e ampliado.

A fim de analisar o impacto do curso sobre a criatividade e o raciocínio lógico, realizou-se as perguntas para saber se o nível dos alunos sofreu alguma alteração com o conhecimento adquirido após o término das aulas. As Figuras 5(b) e 6(b) indicam a contagem de alunos em relação a autoavaliação sobre a melhoria obtida.

Analisando a Figura 5(b), nota-se que não há nenhuma resposta com o valor "1", revelando que a criatividade foi alterada positivamente. Observando a distribuição dos dados, é possível perceber que as barras das maiores notas são as que agrupam os maiores números de contagem, indicando fortemente que o curso inspirou a criatividade na maior parte dos alunos.

A Figura 6(b) apresenta valores balanceados e bem distribuídos entre todas as respostas, diferentemente da Figura 5(b), tendo a maior contagem de alunos na barra roxa ("melhorou muito"). Isso significa que, apesar da grande maioria dos alunos desenvolver uma melhoria no raciocínio lógico com o curso, houve casos de alunos que não mudou ou pouco evoluiu em relação ao nível que possuía anteriormente.

Para verificar a autenticidade do aprendizado apresentado pelo curso, buscou-se analisar em quanto as informações oferecidas são úteis para agregar conhecimento aos 
alunos participantes, ou seja, se o curso realizado é importante na formação intelectual no presente ou possivelmente para eventuais demandas no futuro.

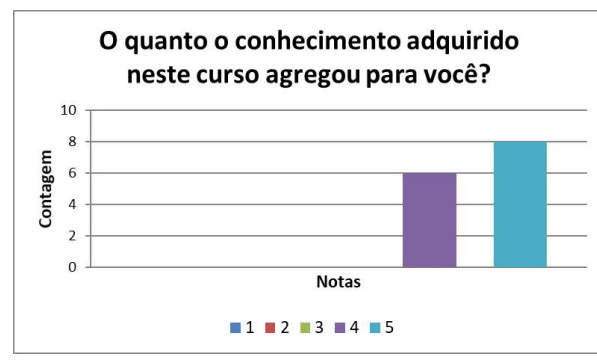

(a) Conhecimento agregado.

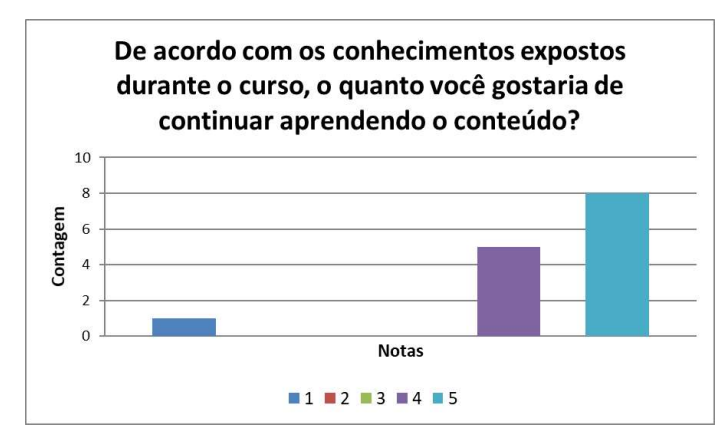

(b) Motivação para aprender novos conteúdos.

Figura 7. Análise do Conhecimento Agregado.

Pelo levantamento apresentado na Figura 7(a), o conhecimento adquirido pelo curso foi bem absorvido e agregado pelos alunos, acrescentando um leque de possibilidades na área da computação como é demonstrado pelos resultados concentrados nas barras de maior valor. Em suma, isso prova que o curso agregou o conhecimento desejado, indicando tornar-se uma informação a ser utilizada pelo participante ao longo de sua vida.

Tendo como proposta do projeto de extensão a realização de um curso de fácil compreensão, torna-se necessário entender sobre como o conhecimento passado pelo professor influencia no aprendizado do aluno. Diante disso, foi implementado o questionamento sobre o quanto os participantes conseguiram absorver o conteúdo fornecido. Figura 8(a) elucida as respostas.

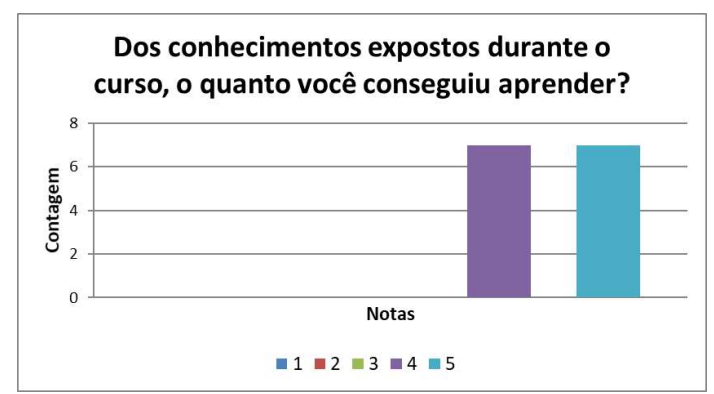

(a) O quanto o aluno conseguiu aprender.

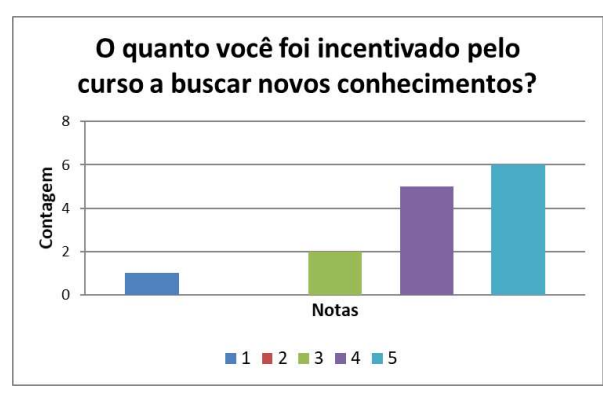

(b) Incentivo a buscar novos conhecimentos.

Figura 8. Análise do Conhecimento.

A partir da observação dos dados expostos na Figura 8(a), é plausível dizer pela concentração das contagens nas barras de maior valor que o professor conduziu o curso de forma efetiva, utilizando das palavras e métodos de ensino que funcionaram, indicando que o conhecimento foi passado aos alunos de forma eficiente. Dessa forma, é aceitável expressar que os participantes estão aptos a desenvolverem projetos utilizando o MIT App Inventor. Esse gráfico é válido para conceder um retorno aos integrantes do projeto de que todo o trabalho realizado foi compensado, cumprindo o seu propósito. 
Como forma de elucidar o impacto do curso na vida do aluno e o quanto a aprendizagem foi instigada na área da computação ou até mesmo na vida acadêmica, buscou-se entender o quanto os participantes foram incentivados a buscarem novos conhecimentos e continuar estudando.

A Figura 8(b) permite analisar que, apesar de haver um resultado abaixo da média, a grande maioria indicou os valores mais altos como resposta, demonstrando fortemente que o curso foi um alavancador para impulsionar os participantes a seguirem os caminhos da área. É importante destacar que há um constante crescimento no campo da computação, abrindo as portas para receber novos alunos e, consequentemente, mais profissionais para atuar no mercado de trabalho nessa área.

Para finalizar a série de perguntas, tentou-se entender a motivação que o curso desenvolveu no aluno para continuar aprendendo o conteúdo e as ferramentas utilizadas na criação de aplicativos com o MIT App inventor. A Figura 7(b) indica os resultados.

Como observado na Figura 8(b) e analisado em 7(b), o curso, além de incentivar a busca por novos conhecimentos na área da computação em geral, também é demonstrado pela alta concentração da contagem nas barras de maiores valores de reposta que os participantes estão dispostos a continuar seguindo e desenvolvendo esforços no aprofundamento dos estudos na ferramenta MIT App inventor. Nota-se que em ambos os gráficos, há uma resposta negativa, indicada pela barra de valor mínimo, reforçando que o aluno não tem interesse em continuar atuando em qualquer área da computação, entretanto, na Figura 7(b) há o desaparecimento da nota "3"e a elevação na nota "5", demonstrando que os alunos preferem seguir ampliando os saberes no conteúdo ensinado no curso.

\section{Considerações Finais}

O trabalho apresentou todos os processos desenvolvidos para o ensino do pensamento computacional, usando o MIT App Inventor de forma criativa e estimulante. O curso apresentou fortes desafios devido à pandemia da Covid-19 e, consequentemente, ao ensino online. Com isso, a forma de avaliação, as metodologias utilizadas no ensino e toda a apresentação do curso foram pensadas e construídas de forma que os envolvidos pudessem se sentir capazes de realmente criarem soluções para o seu cotidiano e, além disso, estimulá-los a evoluir o conhecimento adquirido no curso de outras formas.

As análises das respostas do formulário de autoavaliação bem como toda a participação e engajamento dos alunos no curso permitem concluir que o curso conseguiu cumprir com seu objetivo.

Pretende-se ainda, para as novas versões dos cursos em trabalhos futuros, que seja feita uma consultoria individual para cada integrante de forma que, a ideia pensada na oficina de ideação, saia do campo das ideias e comece a ser desenvolvida utilizando todos os conceitos aprendidos no curso e indo além deles, fazendo-os procurar conceitos novos criando assim, possibilidade para possíveis inovações. Além disso, planeja-se, em uma próxima oferta do curso, a aplicação de um questionário no início das aulas e outro no final, dessa forma os resultados podem ser melhor mensurados visando quantificar melhor os resultados obtidos. 


\section{Referências}

Barcelos, Thiago Schumacher e Silveira, I. F. (2012). Pensamento computacional e educação matemática: Relações para o ensino de computação na educação básica. In XX Workshop sobre Educação em Computação, Curitiba. Anais do XXXII CSBC, volume 2, page 23.

Batista, E. J. S., Castro Jr, A., Cantero, S., Bogarim, C. A. C., and Larrea, A. A. (2016). Uso do scratch no ensino de programação em ponta porã: das séries inicias ao ensino superior. In Anais do Workshop de Informática na Escola, volume 22, page 565.

BRASSCOM (2012). Índice brasscom de convergência digital.https : / / brasscom . org.br/wp-content/uploads/2017/08/ibcd_2012.pdf, Acesso em 27/09/2020.

De Medeiros, L. F. and Wünsch, L. P. (2019). Ensino de programação em robótica com arduino para alunos do ensino fundamental: relato de experiência. Revista Espaço Pedagógico, 26(2):456-480.

Finizola, A. B., Raposo, E. H. S., Pereira, M. B. P. N., Gomes, W. S., de Araújo, A. L. S. O., and Souza, F. V. C. (2014). O ensino de programação para dispositivos móveis utilizando o mit-app inventor com alunos do ensino médio. In Anais do Workshop de Informática na Escola, volume 20, page 337.

França, Rozelma e Tedesco, P. (2015). Desafios e oportunidades ao ensino do pensamento computacional na educação básica no brasil. In Anais dos Workshops do Congresso Brasileiro de Informática na Educação, volume 4, page 1464.

Freire, P. (2002). Peregrinações: os Garros. letos em Ijuí.

Gomes, T. C. and de Melo, J. C. (2013). App inventor for android: Uma nova possibilidade para o ensino de lógica de programação. In Anais dos Workshops do Congresso Brasileiro de Informática na Educação, volume 2.

Pinto, S. C. C. d. S. and Mattos, M. S. (2019). A programaçao de jogos como um instrumento motivador da aprendizagem. Revista Espaço Pedagógico, 26(2):370-394.

SBC (2018). Diretrizes para ensino de Computação na Educação Básica. Disponível em: https://www.sbc.org.br/educacao/ diretrizes-para-ensino-de-computacao-na-educacao-basica. Acesso em: 28 de setembro de 2020.

Silvano, J. (2018). MAKERFÓLIO: Uma proposta para registros de experiências maker para acompanhamento avaliativo. Universidade do Vale do Itajaí (UNIVALI).

Wing, J. M. (2006). Computational thinking. Communications of the ACM, 49(3):33-35.

Wing, J. M. (2011). Research notebook: Computational thinking-what and why. The link magazine, 6. 